\title{
Investigation of thermal comfort in the office by means of a thermal manikin
}

\author{
J. Fišer, J. Pokorný \& M. Jícha \\ Department of Thermodynamics and Environmental Engineering, \\ Brno University of Technology, Czech Republic
}

\begin{abstract}
The paper is focused on the description of a principle of a thermal comfort measurement using a thermal manikin and methodology based on ISO 14505-2. The paper gives an example of the thermal comfort measurement in an office building during the winter season in Central Europe. The influences of environmental parameters and operational conditions of the office on thermal comfort are analysed. The anatomical thermal manikin, divided into 34 independently controlled and measured zones, was used for the measurements and the heat flows from all parts of the manikin were measured. Subsequently based on ISO 14505-2 the equivalent temperatures and thermal comfort were calculated. The measurements have shown the possibility of determining the thermal comfort using a thermal manikin and also influences of main sources of discomfort in the winter season: occasional ventilation through windows and loads from sun radiation. The results also show that measurement with a thermal manikin is a suitable approach for the evaluation of local thermal comfort and allows precise measurements of inhomogeneity and asymmetry of indoor environments.

Keywords: thermal manikin, thermal comfort, indoor environment, equivalent temperature.
\end{abstract}

\section{Introduction}

The thermal comfort of indoor environment is one of the basic conditions which are important for wellbeing, health and mental performance. Indoor environment and thermal comfort could be measured and evaluated by different methods. One of them is a method developed by Nilsson [1]. The merit of the method is determination of equivalent temperature $t_{e q}$. This temperature is related with the 
thermal comfort (mean thermal vote (MTV)) through the comfort zone diagram (see Figure 1) and this connection/relation is a relatively new and promising method [2]. The motivation to develop this was based on the need to enable an evaluation of the thermal comfort in non-uniform indoor environments [3] such as cabins of transport vehicles [4].

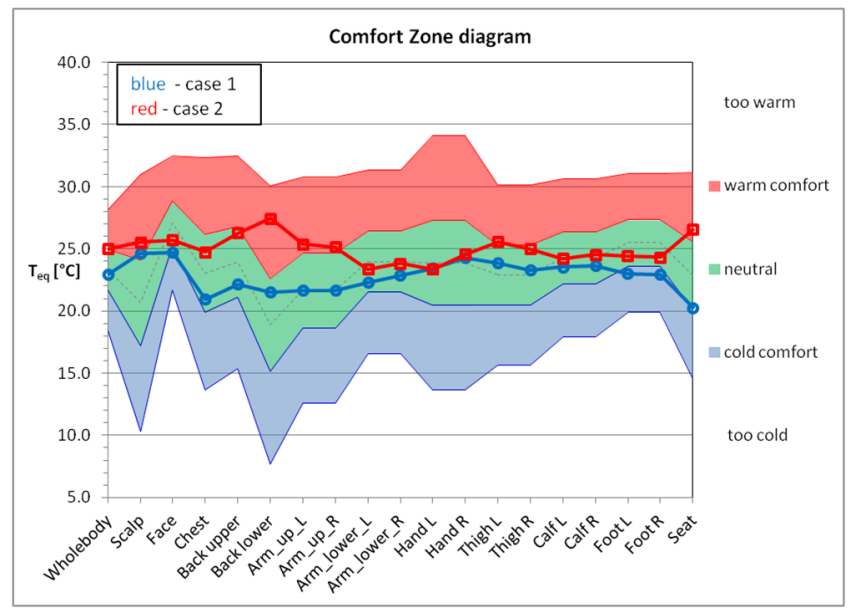

Figure 1: Example of comfort zone diagram.

As it was mentioned above, mean thermal vote is correlated with the equivalent temperature, which is typically measured by the thermal manikin with clothing or by special sensors. Before a measurement in a real environment, the manikin with clothing has to be calibrated in a calibration chamber in order to obtain a total clothing resistance $R T_{\text {cal }}$ for all body parts [5]. These values are important constants in the following equivalent temperature equation

$$
t_{e q}=t_{s}-R T_{\text {cal }} \times q
$$

and are also used to calculate comfort zone diagram

$$
t_{\text {eq,zone }}=t_{s}-R T_{\text {cal }}\left(a+b \times M T V_{\text {zone }}\right)
$$

with respect to a specific clothing worn by the manikin [5]. This thermal comfort evaluation method was adopted in EN ISO regulation 140505-2 - Ergonomics of the thermal environment - Evaluation of the thermal environments in vehicles Part 2 - Determination of equivalent temperature.

\section{Used equipment and method}

The thermal manikin with a shape of an average human body is capable of limb positioning (shoulders, elbows, knees and ankles joints) and is employed when assessing thermal comfort both indoors and outdoors. It can also be used to measure thermal insulation properties of clothing, sport or work equipment. 


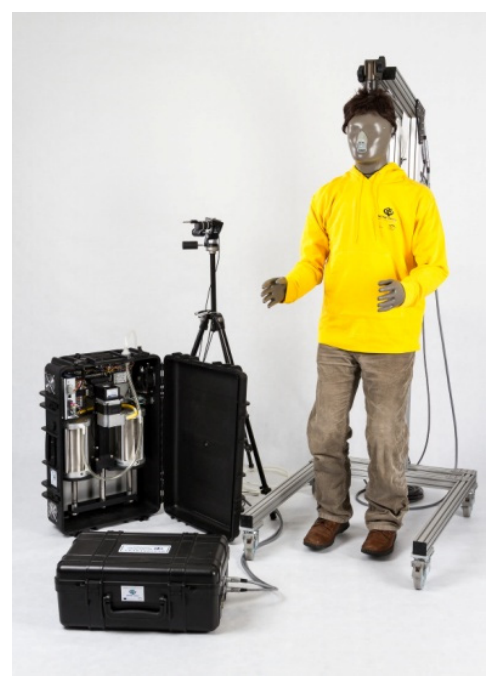

Figure 2: Thermal manikin Newton with measurement equipment.

Another utilisation of the manikin is to measure convection, radiation and conduction heat losses over 34 heated zones (face, head, chest, abdomen, back, arms, forearms, hands, hips, thighs, calves and feet), based on which the total body heat loss can be obtained. The manikin is also equipped with an adjustable breathing system (various inhale and exhale flow rates; breathing through mouth, nose or both) and filters, which allow monitoring the composition of the inhaled particles. The manikin measures total dry heat loss from all segments, which are then used in equation (1) to calculate equivalent temperature $t_{e q}$ on each body segment. These temperatures are then depicted in the comfort zone diagram and MTV for each body segment is obtained. Time constant of the manikin was determined by prior experiments in climatic chamber and its value is around 10 minutes. This imply that the manikin can provide thermal comfort data at least each 5 minutes, when two neighbouring 10 minutes time slots are overlapped by 5 minutes. As result the manikin assesses the thermal state of the environment 24 times per hour. Following manikin's dress was used: cotton T-shirt, shirt with long sleeves, corduroy trousers, cotton socks, underwear, and leather shoes. The manikin is also equipped with two ambient air temperature sensors, one relative humidity sensor, and one air speed sensor. A surface temperature of internal window shutters was monitored with two $\mathrm{T}$ thermocouples which were connected to Testo 735 data logger.

\section{Experiment procedure}

The manikin was installed sitting on a chair in a typical office room equipped with three tables, three computers and chairs for three persons. The windows of the office were oriented directly to the south and could be shaded by the interior horizontal shutters with silver surface finish (see Figure 3). 

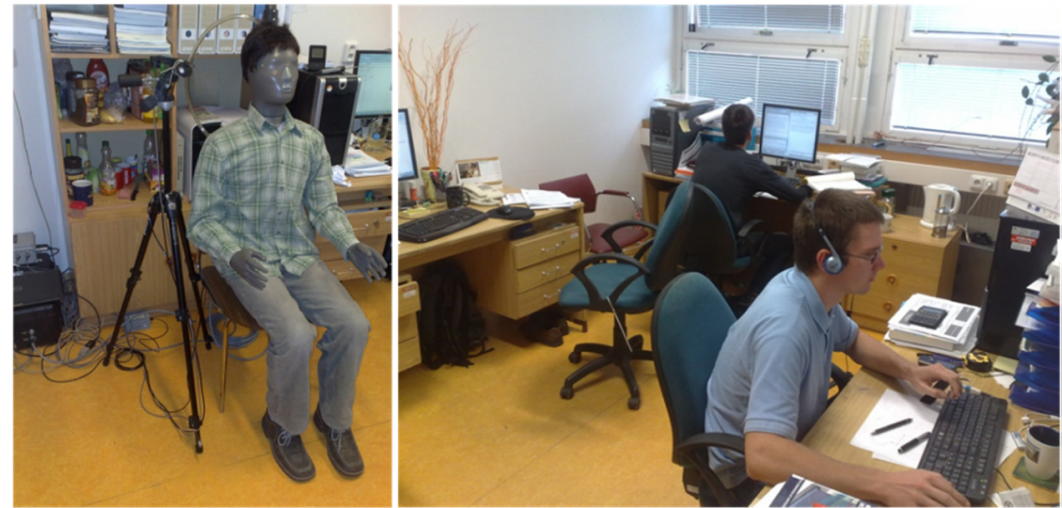

Figure 3: Office layout and location of the manikin installation.

The manikin was switched on at the beginning of the working day and switched off at the end of the day. During the measurements the office was under normal operating conditions, its users did typical activities such as opening the windows for ventilation, closing and opening the shutters and did some adjustments of heating settings. All important events and changes are shown in Table 1.

Table 1: Important events and changes during the days of measurement.

\begin{tabular}{|c|c|c|}
\hline & Event & Time of event \\
\hline \multirow{3}{*}{ Day 1 } & Start of the manikin & $12: 00$ \\
& Windows opening & $14: 20$ \\
& Windows in shadow & $15: 00$ \\
& End of measurement & $18: 20$ \\
\hline \multirow{5}{*}{ Day 2 } & Start of the manikin & $07: 00$ \\
& Direct Sun on manikin & $09: 30$ \\
& Shutters closed & $09: 50$ \\
& End of measurement & $16: 10$ \\
\hline \multirow{3}{*}{ Day 3 } & Start of the manikin & $07: 20$ \\
& Windows/door opened & $13: 15$ \\
& Windows/door closed & $13: 21$ \\
& End of measurement & $14: 00$ \\
\hline
\end{tabular}

\section{Results and discussion}

To demonstrate capabilities of selected approach, each day one specific event was selected and the thermal comfort was evaluated before and after this event. On the first day the selected event was natural ventilation through the open windows. The 
windows were opened at 14:20 thus the thermal comfort was evaluated 10 minutes before ventilation (period 14:10-14:20) and 15 minutes after the windows opening (period 14:30-14:40). The ventilation was draft free because the doors of the office were closed.

The results from the Day 1 are shown in Figure 4. As it can be seen the wholebody comfort was in zone warm but comfortable before the ventilation and dropped to neutral zone after 15 minutes of the ventilation. The decline could be observed on the most parts of the manikin except ones that are insulated by the chair (back lower, seat). In same time the average temperature of air dropped from $25.7^{\circ} \mathrm{C}$ to $24.7^{\circ} \mathrm{C}$. This decline seems negligible but the ventilation had also positive impact on the surface temperature of the internal shutters (dropping from 33.7 to $28.4^{\circ} \mathrm{C}$ ). This had a positive effect on a mean radiant temperature in the office and as a result a drop in the equivalent temperature on the majority of the manikin parts was observed.

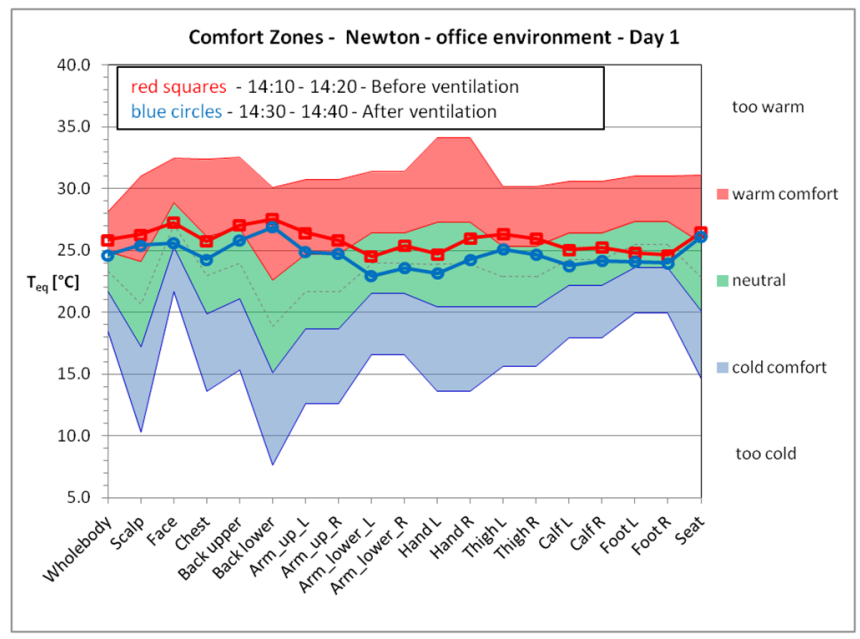

Figure 4: Comfort zone diagram. Day 1-Effect of ventilation.

The weather on the second day of the measurement was partly cloudy hence the windows shutters have had been open since the morning. That caused the manikin's exposure to the direct sun until the shutters were closed at 9:50. The results of this event are shown in Figure 5. As can be seen, the direct sun exposure caused too warm conditions on the parts which were directly hit by the solar radiation. Namely: scalp, face, left upper arm, left lower arm and both hands. At 9:50 the occupants of the office closed the shutters and the result of this event could be observed at 10:05. As can be seen, all overheated parts turned back to neutral zones and also wholebody thermal comfort dropped from too warm in to neutral zone. On the other hand, there were no shifts in the thermal comfort at the parts which were shaded by a surrounding equipment of the office (calf, feet, seat, back lower) which proves that thermal discomfort was caused mainly by the solar radiation. 


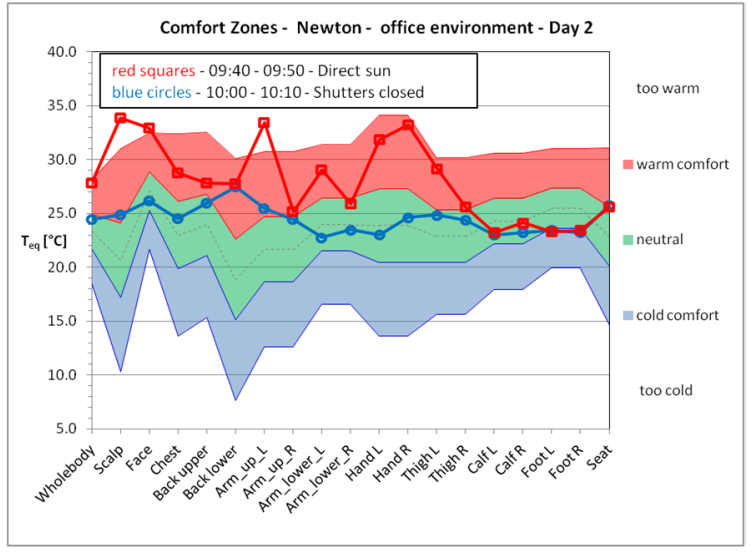

Figure 5: Comfort zone diagram. Day 2-Effect of direct sun.

On the third day, the weather was relatively cloudy but around 13:15 the occupants suggested to ventilate the office what generated a strong draft with a very intensive change of the air.

This intensification of the ventilation resulted in a strong cooling effect on all parts of the manikin so the equivalent temperature dropped on all body parts of the manikin (see Figure 6). Moreover the temperature of the air dropped in a minute from 25.1 to $17.7^{\circ} \mathrm{C}$.

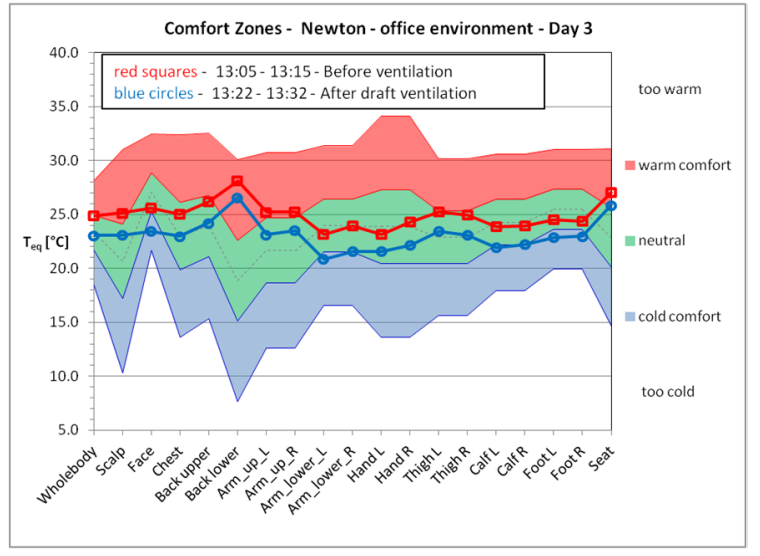

Figure 6: Comfort zone diagram. Day 3 - Effect of strong draft ventilation.

\section{Conclusions}

The measurements have shown the possibility to determine the thermal comfort by using the thermal manikin. The office environment during the three days was monitored and several typical events were captured: gentle ventilation, effect of 
the direct solar radiation and the intensive ventilation with draft. The thermal comfort during all events was evaluated, based on the comfort zone diagram and the main sources of a discomfort in winter season were identified: occasional intensive ventilation through windows and loads from sun radiation. The results also show that the measurement with the thermal manikin is a suitable approach to evaluate the local thermal comfort and allow a precise inspection of the thermal comfort, inhomogeneity and asymmetry of indoor environments.

\section{Acknowledgement}

Authors gratefully acknowledge the support from project CZ.1.07/2.3.00/30.0005 of Brno University of Technology.

\section{References}

[1] Nilsson, H.O., Comfort climate evaluation with thermal manikin methods and computer simulation models, National Institute for Working Life, ISBN 917045-703-4, Stockholm, 2004.

[2] Schellen, L., Loomans, M.G.L.C., Kingma, B.R.M., The use of a thermophysiological model in the built environment to predict thermal sensation - Coupling with the indoor environment and thermal sensation, Building and Environment, 59, 2013, pp. 10-20, ISSN 0360-1323.

[3] Cheng, Y., Niu, J., Gao, N., Thermal comfort models: A review and numerical investigation, Building and Environment, 47, 2012, pp. 13-22, ISSN 03601323.

[4] Liu, W., Mazumdar, S., Zhang Z., State-of-the-art methods for studying air distributions in commercial airliner cabins, Building and Environment, 47, 2012, pp. 5-12, ISSN 0360-1323.

[5] Nilsson, H.O. Thermal comfort evaluation with virtual manikin methods, Building and Environment, 42, 2007, pp. 4000-4005, ISSN 0360-1323.

[6] Zhang, T., Chen, Q., Novel air distribution systems for commercial aircraft cabins, Building and Environment, 42, 2007, pp. 5-12, ISSN 0360-1323. 